DEMOGRAPHIC RESEARCH

VOLUME 43, ARTICLE 20, PAGES 545-580 PUBLISHED 25 AUGUST 2020

https://www.demographic-research.org/Volumes/Vol43/20/

DOI: 10.4054/DemRes.2020.43.20

Research Article

\title{
Fathers' migration and nutritional status of children in India: Do the effects vary by community context?
}

\author{
Lei Lei
}

Sonalde Desai

Feinian Chen

(C) 2020 Lei Lei, Sonalde Desai \& Feinian Chen.

This open-access work is published under the terms of the Creative Commons Attribution 3.0 Germany (CC BY 3.0 DE), which permits use, reproduction, and distribution in any medium, provided the original author(s) and source are given credit.

See https://creativecommons.org/licenses/by/3.0/de/legalcode. 


\section{Contents}

1 Introduction $\quad 546$

2 Fathers' migration and left-behind children in India 549

3 Why does fathers' migration matter to children's nutritional status? $\quad 550$

$4 \quad$ The moderating role of the community context 552

4.1 Communities' socioeconomic development 552

4.2 Communities' gender context 553

$5 \quad$ Data and methods $\quad 554$

5.1 Data $\quad 554$

$5.2 \quad$ Key measures $\quad 556$

$\begin{array}{lll}5.3 & \text { Analytical methods } & 558\end{array}$

$6 \quad$ Results $\quad 559$

$7 \quad$ Conclusions and discussion $\quad 569$

$\begin{array}{ll}\text { References } & 573\end{array}$

$\begin{array}{ll}\text { Appendix } & 579\end{array}$ 


\title{
Fathers' migration and nutritional status of children in India: Do the effects vary by community context?
}

\author{
Lei Lei ${ }^{1}$ \\ Sonalde Desai ${ }^{2}$ \\ Feinian Chen $^{3}$
}

\begin{abstract}
BACKGROUND

Due to international and internal migration, millions of children in developing countries are geographically separated from one or both of their parents. Prior research has not reached a consensus on the impacts of parental out-migration on children's growth, and little is known about how community contexts modify the impact of parental outmigration.
\end{abstract}

\section{OBJECTIVE}

We aim to assess the overall impacts of fathers' previous and current migration experiences on children's nutritional status in India and how the impacts are shaped by community socioeconomic contexts and community gender norms.

\section{METHODS}

Using data from the Indian Human Development Survey collected in 2011-2012, we estimated community fixed-effect regression models predicting the nutritional status of children (ages 10-15) and examined interactions among fathers' migration, children's gender, and community contexts.

\section{RESULTS}

The results showed that children of returned migrants had lower height and body mass index (BMI) than children of nonmigrants. A father's current absence was associated with lower height and BMI for adolescents in communities with high levels of socioeconomic development but not for those in communities with low levels of development. A father's current absence due to migration was especially detrimental to girls in communities with strict norms of female seclusion.

\footnotetext{
${ }^{1}$ Rutgers University, New Brunswick, USA. Email: 1lei@sociology.rutgers.edu.

${ }^{2}$ University of Maryland - College Park, USA.

${ }^{3}$ University of Maryland - College Park, USA.
} 


\section{CONTRIBUTION}

Our findings highlight that the effects of father's out-migration on children are conditioned by the level of communities' socioeconomic development and community gender contexts, which helps to reconcile the previously mixed findings on the effects of parental migration on child outcomes.

\section{Introduction}

Due to the massive flows of internal and international labor migration, millions of children in developing countries are geographically separated from one or both of their parents. Parental out-migration is a family strategy that leads to conflicting consequences. Labor out-migration can provide remittances that improve the economic conditions of the families staying behind (De Brauw and Rozelle 2008; Mberu 2006; Taylor, Rozelle, and De Brauw 2003). However, at the same time, parental migration leads to family disruption and reduces parental input in children's development. Previous studies have reported mixed findings on the overall implications of parental migration for children's well-being and development. Some studies have suggested that parental absence due to migration is detrimental to children's physical health (Davis and Brazil 2016; Gibson, McKenzie, and Stillman 2011; Lu 2015; Tong, Luo, and Piotrowski 2015), psychological well-being (Botezat and Pfeiffer 2014; Dillon and Walsh 2012; Murphy, Zhou, and Tao 2016; Ye and Pan 2011), and educational outcomes (Lahaie et al. 2009; Wen and Lin 2012). Others have reported positive influences from parental out-migration on children's health (Hildebrandt and McKenzie 2005; McKenzie 2005; Mu and De Brauw 2015), educational attainment (Kandel and Kao 2001; Wen et al. 2015), and behavioral outcomes (Wen et al. 2015). Still other studies have found that the impacts of parental migration on children's well-being are weak and inconsistent (Ren and Treiman 2016; Xu and Xie 2015).

Despite the different measurements and analytical strategies employed by these studies (Hamilton and Choi 2015), a more important theoretical reason for the mixed findings is that the impacts of parental out-migration can depend on the characteristics of children, families, and social contexts. A number of studies have shown that the effects of parental migration vary according to whether one or both parents are absent, the gender of the migrant parent, and the presence of grandparents in the origin household (Huang et al. 2018; Tong, Luo, and Piotrowski 2015). However, much less attention has been paid to how the impacts of parental out-migration on children's wellbeing are contingent on social contexts. Cross-national comparative studies have identified different consequences of parental out-migration for children's health across 
social settings (Lu 2015; Nguyen 2016). Research using data from the Child Health and Migrant Parents in South-East Asia (CHAMPSEA) study found that parental outmigration had different impacts on children's psychological well-being, resilience, and risk of stunting in the Philippines, Vietnam, Indonesia, and Thailand (Graham and Jordan 2011, 2013; Jordan and Graham 2012). Scholars have attempted to attribute the distinct findings to the different levels of socioeconomic development in these countries, but they have been unable to empirically test the hypotheses on the contextual effects due to the small number of countries included in the studies. In this paper, we take advantage of the economic and cultural diversity across communities in India to empirically test whether the effects of parental out-migration on early adolescents' nutritional status are contingent on communities' socioeconomic development and gender norms.

Undernutrition among adolescents remains a public health problem in low- and middle-income countries, even though overweight has increased in many contexts. A study in India reported that $37 \%-38 \%$ of children ages $10-16$ are stunted and that $50 \%-$ 64\% suffer from thinness (Haboubi and Shaikh 2009). For those ages 10-14, malnutrition is an important risk factor, contributing to many of the predominant causes of death, such as intestinal infectious diseases, diarrheal diseases, and lower respiratory infections (Christian and Smith 2018). For females, stunting is a risk factor for poor pregnancy outcomes, including small-for-gestational-age and preterm birth (Child Health Epidemiology Reference Group Small-for-Gestational-Age/Preterm Birth Working Group 2015). Children's physical growth is determined by both nutrition and diseases. Because nutritional status and illness are interconnected, underweight and stunting in adolescence reflect poor nutrition, infection, and environmental stress accumulated over time.

We focus on early adolescence (ages 10-15) because this stage is characterized by rapid physical growth, increased nutrient requirements, cognitive and emotional development, and unique experiences within households. Children can attain 15\%-25\% of adult height and about half of adult weight in adolescence (Christian and Smith 2018). To support the rapid growth, nutrition requirements increase dramatically during early adolescence. At these ages, children also become more self-conscious and possibly more sensitive to family disruptions (Davis and Franzoi 1991). Moreover, girls start to internalize gender roles and follow gender-specific norms during adolescence (Abu-Ali and Reisen 1999; Lawler and Nixon 2011). The experiences of children in this age group are quite distinct from those of younger children. While parental absence affects young children via the lack of parental attention and changes in household resources, for slightly older children, there is also a change in time demands because they have to fill in for the absent parent by taking over household or farm chores. 
Using national representative data from the Indian Human Development Survey (IHDS), this study constitutes the first effort to examine the influence of parental outmigration on the nutritional status of early adolescents in India. We focused only on the effects of fathers' migration because labor migration in India is dominated by men, and solo male out-migration is a common strategy to diversify family income in India. (Solo female migration is less common but can happen under certain circumstances. For instance, some young Indian women migrate to metropolitan areas to work as waitresses, in call centers, or in garment factories.) We aimed to answer several research questions represented in Figure 1. First, what are the overall impacts of fathers' migration on the nutritional status of early adolescents in India? Second, how do the effects of father's out-migration vary across communities with different levels of socioeconomic development? Third, how are the effects of father's out-migration on boys and girls conditioned by communities' gender contexts?

Figure 1: The impact of father's out-migration on the nutritional status of children, conditional on community socioeconomic development and gender contexts

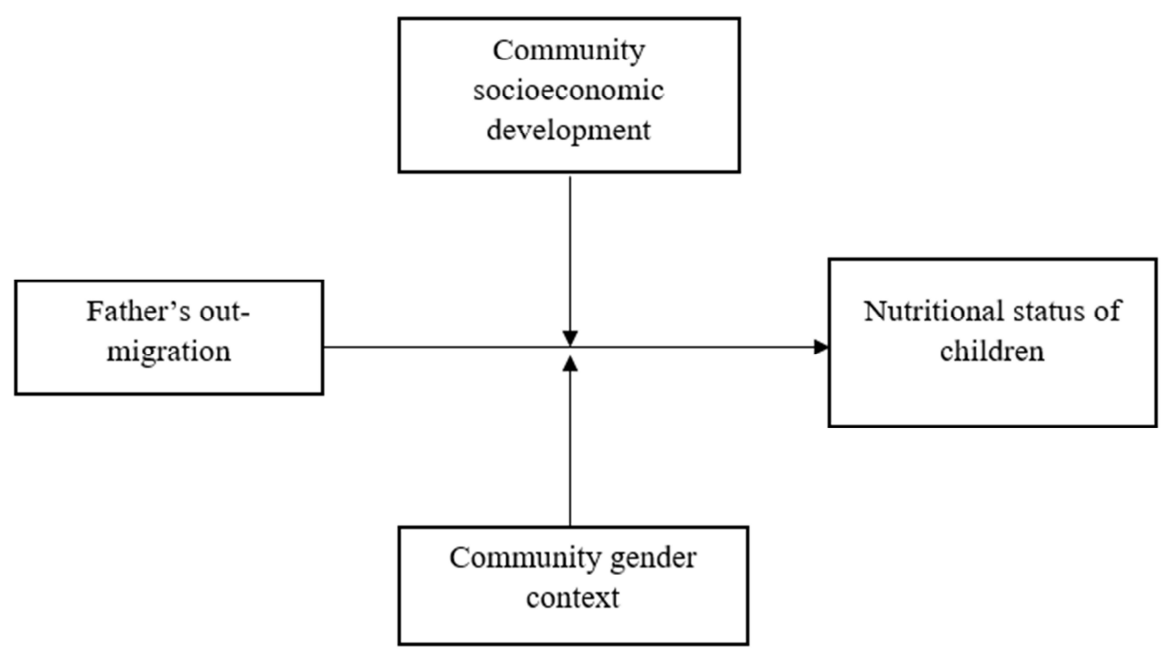




\section{Fathers' migration and left-behind children in India}

The Indian census defines a migrant as a person whose place of residence (village or city) is different than the place enumerated in the previous census. In the 2011 census, India had 454 million migrants based on place of last residence (Office of the Registrar General and Census Commissioner 2011), marking an increase from $30 \%$ of the total population in 2001 to $37 \%$ in 2011 . While two-thirds of the 2011 migrants were women, who usually migrate at the time of marriage, 141 million migrants were men, for whom work and employment were their main reasons for migration. The number of men who migrated for work and business purposes (42.4 million) was five times more than the number of women who migrated for the same reasons ( 8.5 million). Moreover, in 2015, 16 million persons from India were living outside the country, contributing to the most significant diaspora in the world (Department of Economic and Social Affairs 2016).

Solo male migration is a prevalent livelihood strategy adopted by families in India. Due to low incomes, uncertain employment conditions, and expensive housing in migration destinations, male workers often leave their wives and children in places of origin. In regions such as Bihar and Uttar Pradesh, it is common for men to live in large cities for decades, visiting their families only twice a year (Deshingkar et al. 2008; Gulati 1993). Moreover, in many rural areas, Indian men often undertake short-term migration during agricultural downtime or when agricultural labor demand is high in other regions. A study conducted in 2009 suggested that about $11.3 \%$ of a sample of Indian children (ages 5 and 8 years) did not see their fathers daily because they worked far from home, and this figure had increased from 6.5\% in 2007 (Nguyen 2016). Using data from the second wave of the IHDS, collected in 2011-2012, we found that about $13 \%$ of Indian children under age 15 had a migrant father who was currently away or had migrated for at least one month during the past five years.

Geographic diversity in migration behaviors and state-level variation in outmigration have been identified in India (De Haan 1997; Gulati 1993). We argue that instead of treating geographic diversity as a black box, it is important to understand specific aspects of community contexts that shape the social, economic, and cultural diversity of India. States such as Rajasthan, Uttar Pradesh, and Bihar see substantial out-migration. These states are also far more rural and have lower levels of community development than the other states in India, which are factors that push migrants out of origin communities. For example, more than $75 \%$ of the population in these states lives in rural areas, compared to less than $60 \%$ in more developed states, such as Tamil Nadu and Maharashtra. Similarly, gender context tends to vary widely between northern India and southern and eastern India (Dyson and Moore 1983). For instance, there is a stronger adherence to patriarchal family norms and higher levels of son preference and 
control over women's behaviors in northern India than southern and eastern India. Hence, we try to break down the geographic differences in the impact of migration by looking at the socioeconomic development of local areas as well as gender context.

\section{Why does fathers' migration matter to children's nutritional status?}

Empirical research in both developed and developing countries found that children living with single parents have worse developmental outcomes than children in twoparent families (Amato 2001; Dawson 1991). The literature on family dissolution suggests that parental presence ensures the healthy development of children through two primary mechanisms: economic resources and sociocultural resources (McLanahan and Sandefur 1994). Following a divorce, separation, or parental death, children's health can be undermined by diminished economic resources, reduced quality of parenting, and stress and confusion directly related to the family changes (Amato 2000). Parents and children both need to adjust to the changes in family relationships and figure out their new roles and functions. Using family theories on parental absence and children's outcomes as a guiding framework, we elaborate on how parental outmigration may affect children's nutritional status in both positive and negative ways in the context of India (see Figure 2).

Figure 2: Theoretical pathways through which parental migration influences the nutritional status of children

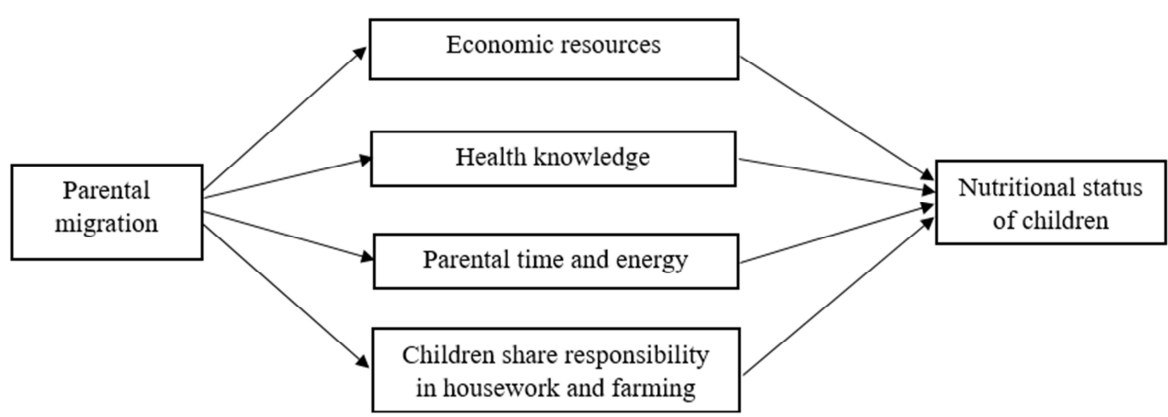


First, unlike types of parent-child separation that result in a decline in economic resources (such as divorce or death of a parent), parental out-migration is often associated with improved economic conditions because of the remittances sent back by migrant parents. Family members' migration has been shown to improve household economic resources and living standards (Aghajanian, Alihoseini, and Thompson 2014; Hadi 1999; Hugo 2002). The increased economic resources allow left-behind families to access quality food, water, household sanitation, and health-care services (AmuedoDorantes and Pozo 2011; Antón 2010; Mu and De Brauw 2015). By bringing economic resources back to origin households, fathers' out-migration can have positive impacts on children's nutritional status. However, previous research has identified different types of labor migration in the Indian context. Using migration as a survival strategy, some male workers undertake seasonal work in nearby villages and towns to supplement their family income (Desai and Chatterjee 2016). In contrast, for life enhancement, other migrants travel a long distance to work in large cities or foreign countries (often for longer periods) (Desai and Chatterjee 2016). The short-term seasonal migrants may be able to send only limited economic remittances, while longterm migration could potentially bring high economic returns despite the higher costs of the trips. Therefore, we expect that long-term migration has more beneficial effects on adolescents' nutritional status than short-term seasonal migration.

Another mechanism through which father's out-migration influences children's nutritional status is the transmission of health knowledge. Existing research provides some evidence that rural-to-urban migrants tend to have more health knowledge than nonmigrant residents in rural areas in the context of Mexico (Hildebrandt and McKenzie 2005). Another study showed that the duration of residence in a destination city in China is positively associated with migrant women's knowledge about reproductive health (Wang et al. 2005). In developing countries, migrants living in migration destinations usually are exposed to more socioeconomically developed contexts than in their origin communities. Migrants tend to learn health knowledge through the mass media and social interactions with local residents and transmit the knowledge to staying-behind caregivers. We admit that this might not be true in the context of India, where migrants could face language barriers in migration destinations. Besides, migrants living in isolated areas, such as workers' dorms or slums, may have limited interaction with local residents or limited exposure to the mass media. Nevertheless, the richer health knowledge among migrants compared with nonmigrants can be attributed not only to migrants' interaction with local residents in the destinations but also to the interactions among migrants themselves. Menjívar (2002) suggested that Guatemalan immigrants in the United States regularly share medical knowledge in their social networks, helping one another with information about 
treatments and health advice. This could happen among migrant workers in India as well.

The absence of fathers due to migration also leads to reduced parental time and energy devoted to children. The remaining caregivers, whether mothers or grandparents, have to undertake additional household responsibilities, chipping away at the time they can spend on child care. For example, without fathers to take care of household management tasks, such as shopping for food, mothers might have less time to prepare quality food, bathe children frequently, maintain a sanitary home environment, or use health services to boost children's health. Prior research has found that children in migrant households receive less breast-feeding and fewer immunizations (Hildebrandt and McKenzie 2005). Besides, the reduced monitoring and supervision due to absent fathers can increase the likelihood of delinquency and deviant behaviors among children (Coley and Medeiros 2007), leading to higher risks of accidents. Left-behind children are also more likely to engage in unhealthy behaviors, including drinking, smoking, and illicit drug use (Wen and Lin 2012).

When fathers are away, older children sometimes have to take on more responsibilities, performing housework, farming, and caring for younger siblings (Antman 2011; Chang, Dong, and MacPhail 2011; Ye and Pan 2011). These added responsibilities can reduce children's time and energy available for studying, playing, and socially interacting with peers; this reduction can be detrimental to their physical development. In areas of India with poor facilities, household members still spend substantial amounts of time fetching water and firewood. By doing these household chores, children of migrants are more susceptible to infections and substantial energy consumption, which contributes to undernutrition.

\section{The moderating role of the community context}

\subsection{Communities' socioeconomic development}

How the countervailing mechanisms for the effects of parental out-migration play out largely depends on communities' social and economic environments. In resource-poor communities, adolescents' health suffers primarily from poor housing conditions, inferior personal hygiene, and lack of access to clean water and nutritious food. A lack of health knowledge may also impair adolescents' health and nutrition in resource-poor contexts. But the increased economic resources from remittances and the transmission of health knowledge may outweigh the negative impacts of reduced parental attention, resulting in a positive net impact of parental out-migration on children's nutritional status in these contexts. 
In contrast, in communities with relatively high levels of socioeconomic development, where standards of living and levels of health knowledge are less likely to threaten children's health, the impacts of the reduced quality of parenting may become more prominent. In economically developed areas (for example, metropolitan areas), remittances have limited ability to improve the quality of life due to the high costs of living. Further, because the caregivers (mainly mothers) in more developed communities already have relatively high levels of education, the health of their children may not benefit from the transmission of health knowledge. Therefore, fathers' absence due to out-migration might have a negative overall effect on the nutritional status of left-behind children in communities with higher levels of socioeconomic development. In a comparative study, $\mathrm{Lu}$ (2015) found that parental migration had a more positive impact on children's physical growth in Indonesia, a resource-poor context, than it had in Mexico, a context with higher levels of economic development. CHAMPSEA researchers showed that parental out-migration had different impacts on the physical growth and mental health of children in the Philippines and children in Thailand, Vietnam, and Indonesia. They encouraged future research to examine contextual factors that might explain this finding (Graham and Jordan 2011, 2013). We hypothesize that father's out-migration has more positive influences on early adolescents' health in less developed communities than in wealthier communities for the reasons stated above, and we empirically test this hypothesis in this study.

\subsection{Communities' gender context}

In addition to regional variation in development, India exhibits large geographic diversity in culture, values, and norms. In Indian society, sons are valued more than daughters due to the patrilineal and patriarchal family norms, but son preference is much stronger in northern India than in other parts of India (Lahaie et al. 2009). In communities with strong son preference, household resources tend to be unequally allocated between boys and girls. Previous studies have found that girls often are given less nutritious food than boys (Kandel and Kao 2001) and have higher mortality than boys in the majority of states in India (Arnold, Choe, and Roy 1998). When son preference exists in migrant households, the economic resources and health-related information transmitted from migrant fathers might be more likely to be used to boost the nutritional status of boys than girls. Moreover, in a context where boys are prized, girls are more likely to help mothers and grandparents with housework, farming, and caregiving in their fathers' absence, which could undermine girls' health and nutritional status. We therefore expect that out-migration by fathers has more positive effects on the nutritional status of boys than on the nutritional status of girls. 
However, these gender effects can further be contingent on a community's gender context, as indicated by the strength of son preference and gender norms. In communities with widespread son preference, the unequal allocation of family resources between boys and girls could be starker, and girls might be required to undertake more household chores and caregiving responsibilities. A father's absence thus could have more detrimental effects on the health of girls than the health of boys.

Another important aspect of communities' gender norms is the practice of purdah, or female seclusion, which is the most visible marker of gender in India. Motivated by the ideology that women should be modest, obedient, docile, and attached to the home, South Asian societies have a strong normative preference for female seclusion (Sharma 1990). Purdah is performed in a variety of ways, including "wearing a full burqa, covering one's face with a shawl or sari when in the presence of men, lowering voices and eyes in the presence of men, remaining in separate rooms or behind a screen when unrelated men are present, or not going to public places unaccompanied" (Stroope 2015: 290). The practice of purdah varies widely across regions and communities in India due to differences in social systems, kinship structures, and gender norms (Desai and Andrist 2010).

In communities with a norm of purdah practice, a father's absence could be more detrimental to the health of left-behind girls than left-behind boys for several reasons. First, women in communities in which purdah is widely practiced have little freedom of physical mobility and few opportunities to obtain an education and participate in labor market activities, so parents have fewer incentives to invest in girls than in boys. The family disruption and possible shortage of family resources resulting from parental outmigration can undermine the nutritional status and health of girls more than boys in these social contexts. Second, the belief that women belong to the domestic sphere and should be secluded may reinforce gender role expectations that girls should take care of housework when there is a labor shortage in the household. Third, the practice of purdah affects mothers' ability to manage household issues and take care of children. For instance, in some regions, women may not do grocery shopping or go to the post office without male companions. When this situation is combined with son preference, fathers' absence compromises girls' health before boys' health.

\section{Data and methods}

\subsection{Data}

This study analyzed data from the IHDS interviews collected by the National Council of Applied Economic Research (NCAER) in India and the University of Maryland in 
2004-2005 and 2011-2012 (Desai, Vanneman, and National Council of Applied Economic Research 2011/12). Using a multistage sampling strategy, the IHDS drew a representative sample from 34 states and union territories, encompassing 971 urban blocks and 1,503 villages in 388 districts in India. ${ }^{4}$ The 2004-2005 survey collected data on 41,554 randomly selected households with more than 200,000 individuals, and $83 \%$ of these households, including any split households, were reinterviewed in 20112012. An additional sample of 2,148 households was included to refresh the urban sample where the recontact rates were lower. This process resulted in a 2011-2012 sample of 42,152 households containing 215,748 individuals. The household questionnaire covered a wide range of topics, including household economic activities, social networks, living standards, and household members' demographic characteristics, education, work status, income, and health. In each survey, at least one eligible women aged 15 to 49 from each household was interviewed, and they responded to additional questions about health, gender relations, fertility, and natal care and provided information about their children's health and education. In both waves, the IHDS team carried out village-level focus group discussions among village government officials, local businessmen, and other adults to collect information about village structure, infrastructure, labor market characteristics, land use, and agricultural production, among other factors.

This study used the second wave of IHDS data, collected in 2011-2012, because the first wave of the survey did not have information on respondents' recent migration experiences. We focused analysis on 12,217 children in early adolescence (ages 10-15), a stage of rapid physical growth, increased nutritional requirements, and cognitive and emotional development. We restricted the analysis to 11,452 adolescents who had biologically plausible values on anthropometric measures, who had information about fathers, ${ }^{5}$ and whose fathers were married to their mothers at the time of the IHDS-II interview. ${ }^{6}$ Removing the cases with missing values on other variables further reduced the analytical sample to 11,295 adolescents. These adolescents belonged to 7,732 households and 2,131 communities in the analytical sample. On average, each

\footnotetext{
${ }^{4}$ In rural areas, the IHDS household sample is a composite of several different subsamples, including a reinterview sample of households previously interviewed, mostly in 1994-1995 for the Human Development Profile of India (HDPI; N = 13,900), and new households comprised of a replacement sample for lost village listings in HDPI, a refresher sample from HDPI districts, and an extension sample from states and union territories not sampled in $1994(\mathrm{~N}=13,110)$. The HDPI employed a complicated multistage sample, and the new households were also drawn using a multistage sampling method. In urban areas, cities or towns were sampled from states with probabilities proportional to population, and 45 households were randomly selected from each town ( 15 households in each census-defined neighborhood within the town).

${ }^{5}$ Among all children ages $10-15$, about $3.78 \%$ are missing information on their fathers, because either the fathers have died (3.37\%) or the parents were separated or divorced.

${ }^{6}$ Among children ages $10-15,3.77 \%$ were excluded because their mothers were widowed, separated, or divorced.
} 
community contained 5.3 adolescents. The number of adolescents in a community ranged from 1 to 57 , with a standard deviation of 4.44 .

\subsection{Key measures}

The dependent variables for this study are height-for-age and body mass index (BMI)for-age. We converted both variables into z scores using age- and gender-specific WHO standards (de Onis et al. 2007). Cases with biologically implausible scores for the dependent variables (beyond -6 or 6 for height-for-age $z$ scores and beyond -5 or 5 for BMI-for-age z scores) were removed. Height-for-age and BMI-for-age are measures of children's physical growth. Height-for-age is used to identify children who suffer from stunting (defined as -2 standard deviation from the mean). BMI-for-age is an indirect measure of body fatness, which can be used to detect thinness ( -2 standard deviation below the mean). Children's physical growth is immediately impacted by both dietary intake and illness. Low physical growth is a result of multiple risk factors, including insufficient nutritional intake, energy consumption (activities in which children participate), quality of living environment (such as hygiene), and experiences of infectious and chronic diseases. Because adolescents experience few chronic and infectious diseases, it is appropriate to use physical growth as an indicator of health.

The focal independent variable, father's migration status, was constructed using information from two survey questions. First, in the household questionnaire, the respondent was asked: "Does any woman/man in the household have a husband/wife who lives outside the household?" If the husbands/fathers were currently away, we considered them current migrants in this study. ${ }^{7}$ In addition, the IHDS-II interview asked whether any household members had left to find seasonal/short-term work for at least one month during the past five years and returned to live in the household. Fathers identified in this question were defined as returned migrants. Fathers who had not made any migration trips for at least one month in the past five years and were not currently absent were considered nonmigrants in this study. We constructed a categorical variable distinguishing among nonmigrants, returned migrants (fathers who had made a migration trip in the past five years and returned by the time of the IHDS-II), and current migrants (migrant fathers absent at the time of the IHDS-II interview). Due to their long periods of absence, long-term and often long-distance migrants were most

\footnotetext{
${ }^{7}$ Because there were no requirements for duration or destination of migration in this question, currently absent fathers were considered migrants regardless of when they left the households and how far away from home they were. Similarly, there was no requirement for the destination in our definition of returned migrants. Based on the recorded destinations, among all migrant fathers in this sample, $55 \%$ migrated to urban destinations, $19 \%$ moved to rural destinations, and $26 \%$ had unknown destinations.
} 
likely to be captured in the survey as current migrants. The returned migrants were often seasonal workers who took jobs in nearby villages and towns for shorter periods. (In our sample, the returned migrants were absent for 1.3 years on average, and current migrants were on average absent for three years before the IHDS-II interview.)

We examined the conditioning roles of two aspects of communities' characteristics: community socioeconomic development and community gender context. A community's socioeconomic development was a composite measure based on location (urban versus rural) and development indicators (such as availability of electricity, piped water, modern gas, and telephones in the community). Urban/rural designations were made according to the 2011 census. ${ }^{8}$ We further divided urban areas into large cities (including Mumbai, Kolkata, Delhi, Chennai, Bangalore, and Hyderabad) and smaller cities. Rural areas were divided into villages with high levels of infrastructure facilities and those without. Villages with at least six of the following ten facilities were considered more developed, and the remaining villages were considered less developed. The ten infrastructure facilities were electricity, paved roads, a kirana (grocery) shop, a bus stop, landline telephone access, mobile telephone access, a post office, a police station, a bazaar, and a bank. In this way we distinguished between metropolitan urban communities, other urban communities, more developed rural communities, and less developed rural communities.

The communities' gender context was captured by two variables. In the IHDS, all eligible women (ages 15-49) in the sample were asked the number of sons and daughters they would ideally like to have. Using this information, we measured community-level son preference by calculating the proportion of women in the community who desired more sons than daughters. The second variable, communities' gender norms, was also an aggregated measure from the sample, based on the proportion of women in a community who practiced purdah.

We included control variables capturing children's demographic characteristics, family socioeconomic status, mother's characteristics, and household structure. These variables were selected because they determine children's access to family economic and social-cultural resources, which in turn affect nutritional status. Children's demographic characteristics were measured by gender $(1=$ girls $)$ and age in months, factors that are directly related to height and weight. Family socioeconomic status was captured by the father's education, mother's education, household assets, and caste and religious group. Father's education and mother's education were the numbers of years of education received by the father and mother. Household assets were originally a sum

\footnotetext{
${ }^{8}$ In the census, an area is classified as an urban unit if it is declared by the state government under a statute to be a municipality, corporation, cantonment, or notified town area. In addition, places are classified as urban if they satisfy all the following criteria: a minimum population of 5,000 , at least $75 \%$ of the male working population engaged in nonagricultural economic pursuits, and a density of population of at least 400 per square kilometer.
} 
of items on a list of 30 consumer goods (a TV, motor vehicle, air cooler, telephone, and so on) and housing features (such as a flush toilet, electricity, and piped indoor water). We constructed a categorical variable to reflect the quintiles of household assets. Castes and religious groups were measured by a categorical variable indicating if the family belonged to the forward caste, other backward classes (OBC), ${ }^{9}$ or the Dalit, Adivasi, Muslim, or another religious group (including Christians, Sikhs, and Jains). Mother's age and height (measured in centimeters) were controlled for because they determined children's biological endowments. We also included a few variables reflecting the household structure. A dummy variable was used to indicate the presence of grandparents in the household. The total number of children under age 15 living in the household and whether the mother had any children under age 5 were controlled for. A large number of children in a household tends to dilute the resources allocated to each child, and the presence of young children may attract parental attention away from adolescents.

\subsection{Analytical methods}

We first calculated descriptive statistics for the characteristics of children, households, and communities (see Table 1). We then employed ordinary least squares (OLS) regression models to assess the impacts of father's migration status on children's height-for-age and BMI-for-age while controlling for family characteristics and community fixed effects.

The community fixed-effect model can be expressed using the following equation:

$$
y_{i j}=\beta_{0}+\beta_{1} \operatorname{RetMig}_{i j}+\beta_{2} \operatorname{CurMig}_{i j}+\beta_{3} X_{3 i j}+\cdots+\beta_{p} X_{p i j}+\gamma_{j}+\varepsilon_{i j},
$$

where $y_{i j}$ represents the health outcome of child $i$ in community $j, \operatorname{RetMig} g_{i j}$ and CurMig $_{i j}$ are dummy variables for the migration status of the child's father, $X_{3 i j}$ through $X_{p i j}$ are control variables measuring the individual and family characteristics of the child, and $\gamma_{j}$ is the fixed effect of community $j$. The main effect of the father's migration status on child health is reflected by the coefficients $\beta_{1}$ and $\beta_{2}$. The estimation of these coefficients is based on differences among children living in the same community because all between-community variation is captured by the community fixed effects. We also use robust clustered error to allow for correlation among children in the same household.

\footnotetext{
${ }^{9} \mathrm{OBC}$ is a term used by the government of India to classify castes that are educationally or socially disadvantaged.
} 
Research on the impacts of migration is challenged by the issue of selectivity bias because not all households are equally likely to send migrants and the factors that affect the likelihood of migration may also be associated with children's health outcomes. Migration tends to be chained and clustered, so many predictors of migration are community-level factors, such as local wage levels, location, transportation conditions, social networks, and economic shocks. By including community fixed effects, we were able to rule out all the observed and unobserved community features that could simultaneously influence fathers' tendency toward out-migration and children's nutritional status. We thus could compare children of migrants and children of nonmigrants living in the same community. We also tried to control for a variety of household and parental characteristics to eliminate factors that could confound the relationship between fathers' out-migration and children's nutritional status.

To test the conditioning effects of community contexts, we included in subsequent models the interaction between father's migration status and community socioeconomic development, and the three-way interactions among father's migration status, children's genders, and community gender contexts (measured by community-level son preference and the practice of purdah). Because community socioeconomic development and gender contexts are community-level variables, their main effects are absorbed by the community fixed effects and cannot be estimated. Yet we are able to estimate how the effect of father's migration is conditioned by these community characteristics.

\section{Results}

Table 1 presents the weighted descriptive statistics of the dependent and independent variables. The weighted mean height-for-age $\mathrm{z}$ score was -1.62 , and the average BMIfor-age $\mathrm{z}$ score was -1.08 , indicating that children in India had average heights and weights below the median heights and weights for children of the same gender and age in a global reference population. Although overweight becomes a health issue in many parts of the world, in the context of India, a low BMI-for-age is considered a negative health outcome because it indicates undernutrition and is associated with morbidity among adolescents in developing countries (Christian and Smith 2018). According to the WHO growth trajectory, a BMI-for-age below -2 SD is defined as "thinness" and -3 SD is considered "severe thinness." About $25 \%$ of children in our sample were thin and about $8.3 \%$ were severely thin (statistics not shown in tables). 
Table 1: Weighted descriptive statistics of the analytical variables, IHDS-II, 2011-2012

\begin{tabular}{|c|c|c|}
\hline Variable & Mean or percentage & $\begin{array}{l}\text { Standard } \\
\text { deviation }\end{array}$ \\
\hline Height-for-age z score & -1.62 & 1.43 \\
\hline BMI-for-age $z$ score & -1.08 & 1.41 \\
\hline \multicolumn{3}{|l|}{ Father's migration status } \\
\hline Nonmigrant & $87.15 \%$ & \\
\hline Returned migrant & $5.69 \%$ & \\
\hline Current migrant & $7.16 \%$ & \\
\hline \multicolumn{3}{|l|}{ Gender } \\
\hline Boys & $52.42 \%$ & \\
\hline Girls & $47.58 \%$ & \\
\hline Age (in months) & 147.01 & 21.06 \\
\hline Mother's age & 36.33 & 5.45 \\
\hline Mother's height & 151.53 & 7.58 \\
\hline Mother's years of education & 4.70 & 4.75 \\
\hline Father's years of education & 7.07 & 4.75 \\
\hline Coresidence with grandparents & $28.07 \%$ & \\
\hline $\begin{array}{l}\text { Number of children (under age 15) in the } \\
\text { household }\end{array}$ & 2.79 & 1.21 \\
\hline Any children under age 5 & $4.48 \%$ & \\
\hline Birth order & 2.54 & 1.66 \\
\hline \multicolumn{3}{|l|}{ Caste and religious group } \\
\hline Forward caste & $19.60 \%$ & \\
\hline OBC & $37.25 \%$ & \\
\hline Dalit & $22.36 \%$ & \\
\hline Adivasi & $6.12 \%$ & \\
\hline Muslim & $12.83 \%$ & \\
\hline Christian, Sikh, Jain & $1.83 \%$ & \\
\hline \multicolumn{3}{|l|}{ Household assets } \\
\hline Poorest & $19.21 \%$ & \\
\hline Second quintile & $17.86 \%$ & \\
\hline Middle quintile & $24.59 \%$ & \\
\hline Fourth quintile & $20.09 \%$ & \\
\hline Richest & $18.25 \%$ & \\
\hline
\end{tabular}


Table 1: (Continued)

\begin{tabular}{lcc}
\hline Variable & Mean or percentage & $\begin{array}{c}\text { Standard } \\
\text { deviation }\end{array}$ \\
\hline Community context & & \\
Level of socioeconomic development & $6.86 \%$ & \\
Metropolitan urban & $24.14 \%$ & \\
Other urban & $31.18 \%$ & 0.18 \\
More developed rural & $37.83 \%$ & 0.37 \\
Less developed rural & 0.28 & \\
Son preference (proportion of women expressing & & \\
son preference) & 0.64 & \\
Purdah practice (proportion of women performing & & \\
purdah) & & \\
Number of children & 11,295 & \\
Number of communities & 2,131 & \\
\hline
\end{tabular}

About $13 \%$ of children in early adolescence had fathers who had migrated within the five years before the IHDS-II. The fathers of $5.69 \%$ of children had returned, and the fathers of $7.16 \%$ of children were still absent at the time of the IHDS-II. (As shown in Appendix A, the percentages of returned migrant fathers and current migrant fathers were similar for boys and girls. But the percentages of returned and current migrant fathers were lower in more developed urban communities than in less developed rural communities.) About half of children were boys, and their average age was 12.25 years (147 months). On average, mothers were 36 years old and were 151.53 centimeters tall. Mothers on average had received less than five years of education, while fathers typically obtained seven years of education. About one-third of children co-resided with at least one grandparent. On average, each household had 2.79 children younger than age 15 , and $4.48 \%$ of children in the sample lived in households that had children younger than age 5 . The average birth order was 2.54 , indicating the relatively high total fertility rate in India. About one-fifth of households belonged to the forward caste, $37 \%$ belonged to OBC, $22 \%$ were Dalits, $6 \%$ were Adivasis, $12.8 \%$ were Muslims, and the remaining $1.8 \%$ were in other religious groups. The households in the analytical sample were more likely to be in the middle quintile of assets than in the poorest and richest quintiles.

Regarding the community contexts, about $7 \%$ of communities were characterized as metropolitan urban communities, $24 \%$ as other urban communities, $31 \%$ as more developed villages, and $38 \%$ as less developed villages. In a typical community, $28 \%$ of women expressed son preference, and $64 \%$ practiced purdah. (The values for both variables ranged from $0 \%$ to $100 \%$.) 
Table 2: Community fixed-effect regression models predicting height-for-age z scores among children (ages 10-15) in India, IHDS-II, 2011-2012

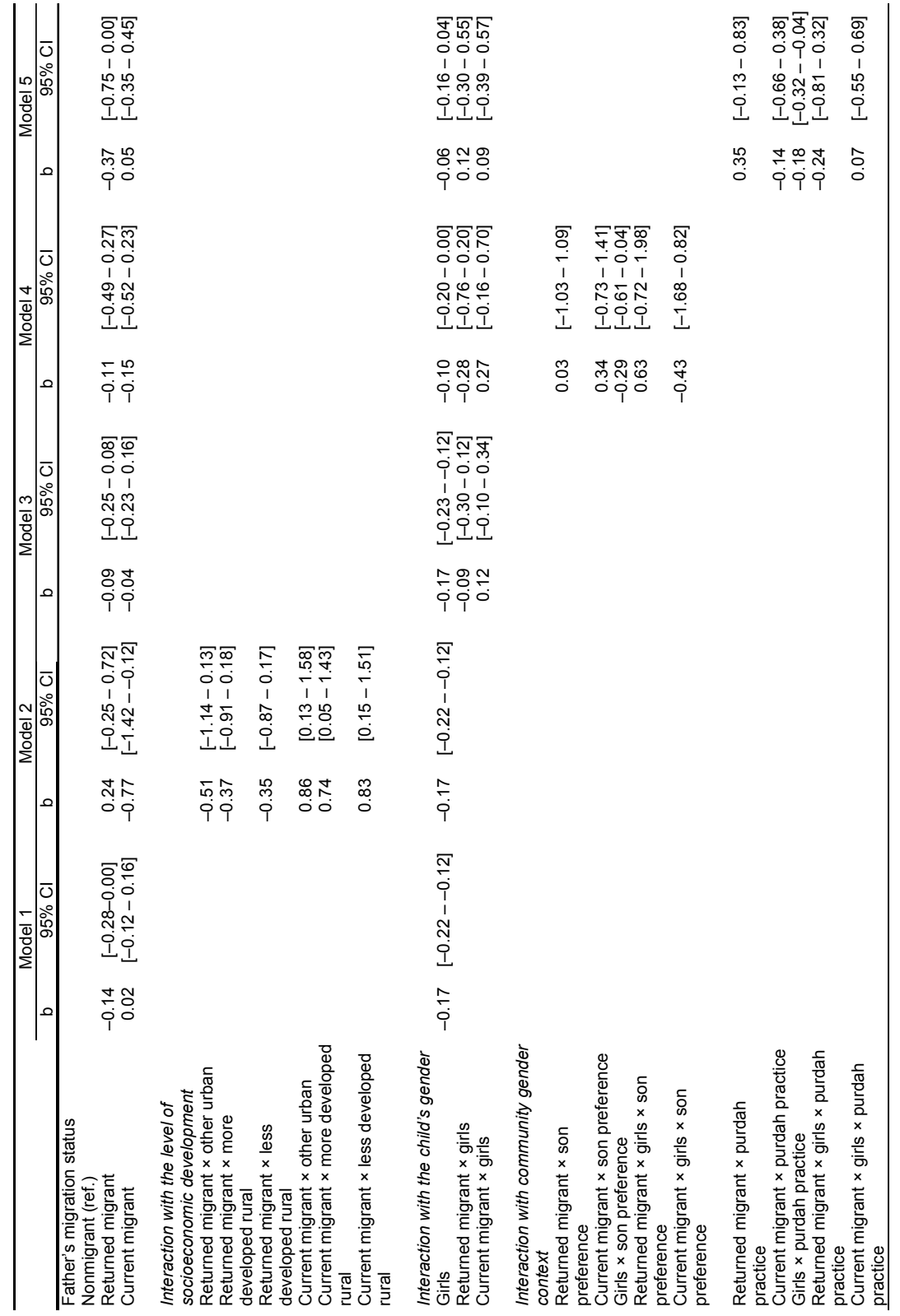


Table 2: $\quad$ (Continued)

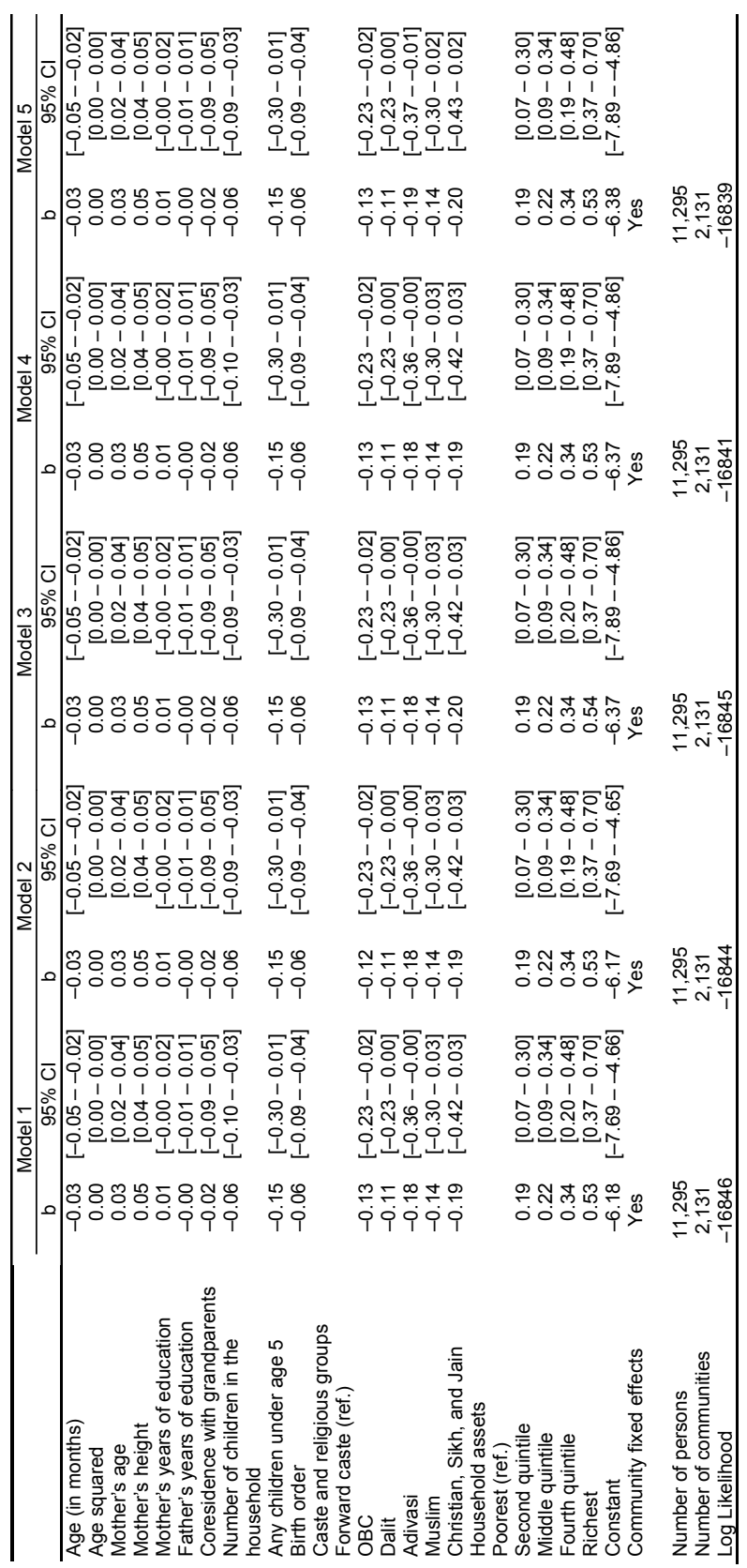


Table 2 presents the community fixed-effect linear regression models predicting children's height-for-age $\mathrm{z}$ scores. Model 1 includes the main predictor (father's migration status) and all the individual- and family-level control variables. According to the coefficient, children of returned migrants tended to have lower height-for-age scores than children of non-migrants $(\mathrm{b}=-0.14, \mathrm{CI}=(-0.28,0.00))$, whereas father's current absence due to migration was not associated with shorter stature in children.

In Model 2 in Table 2, we included the interaction terms between father's migration status and community level of socioeconomic development. The coefficients for the interaction terms indicated that the effects of father's current absence varied by the community's level of socioeconomic development. The marginal effects of father's current absence on the community's level of economic development were predicted at the means of all the other control variables and are presented in Figure 3. In metropolitan urban communities, father's current absence due to migration was associated with lower height-for-age among children, whereas in other urban communities and both more developed and less developed rural communities, father's current migration had positive or much smaller negative effects on children's height. This is partially consistent with our expectation that a father's out-migration has a more detrimental impact on children's nutritional status in socioeconomically developed communities than in less developed communities.

\section{Figure 3: Marginal effects of father's current migration on height-for-age among children 10-15 years old in India, by community socioeconomic development}

0.2

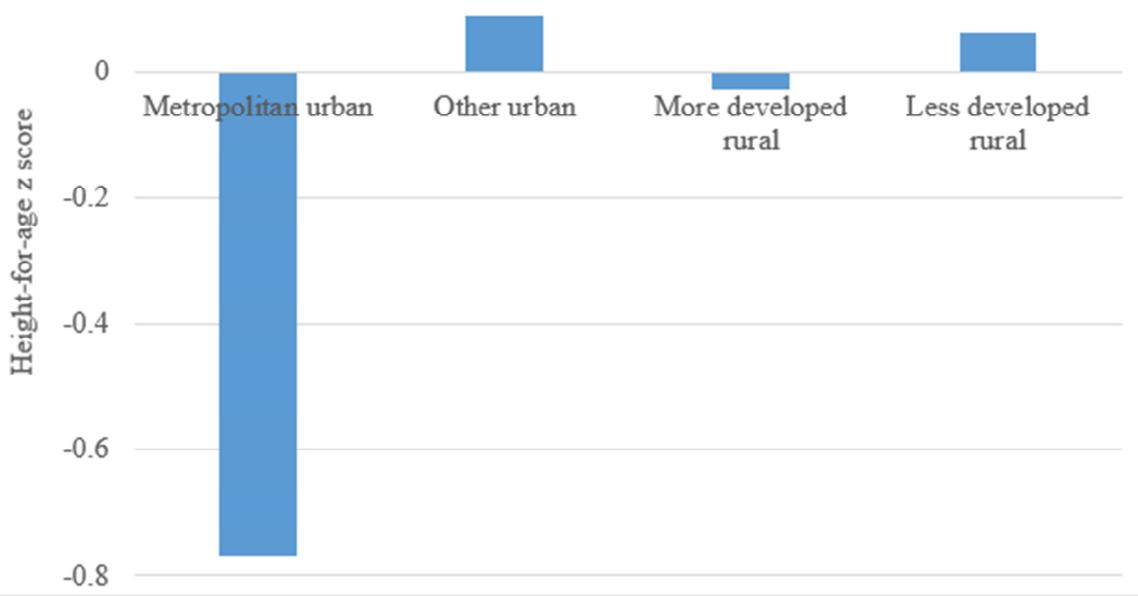


Table 3: Community fixed-effect regression models predicting BMI-for-age z scores among children (ages 10-15) in India, IHDS-II, 2011-2012

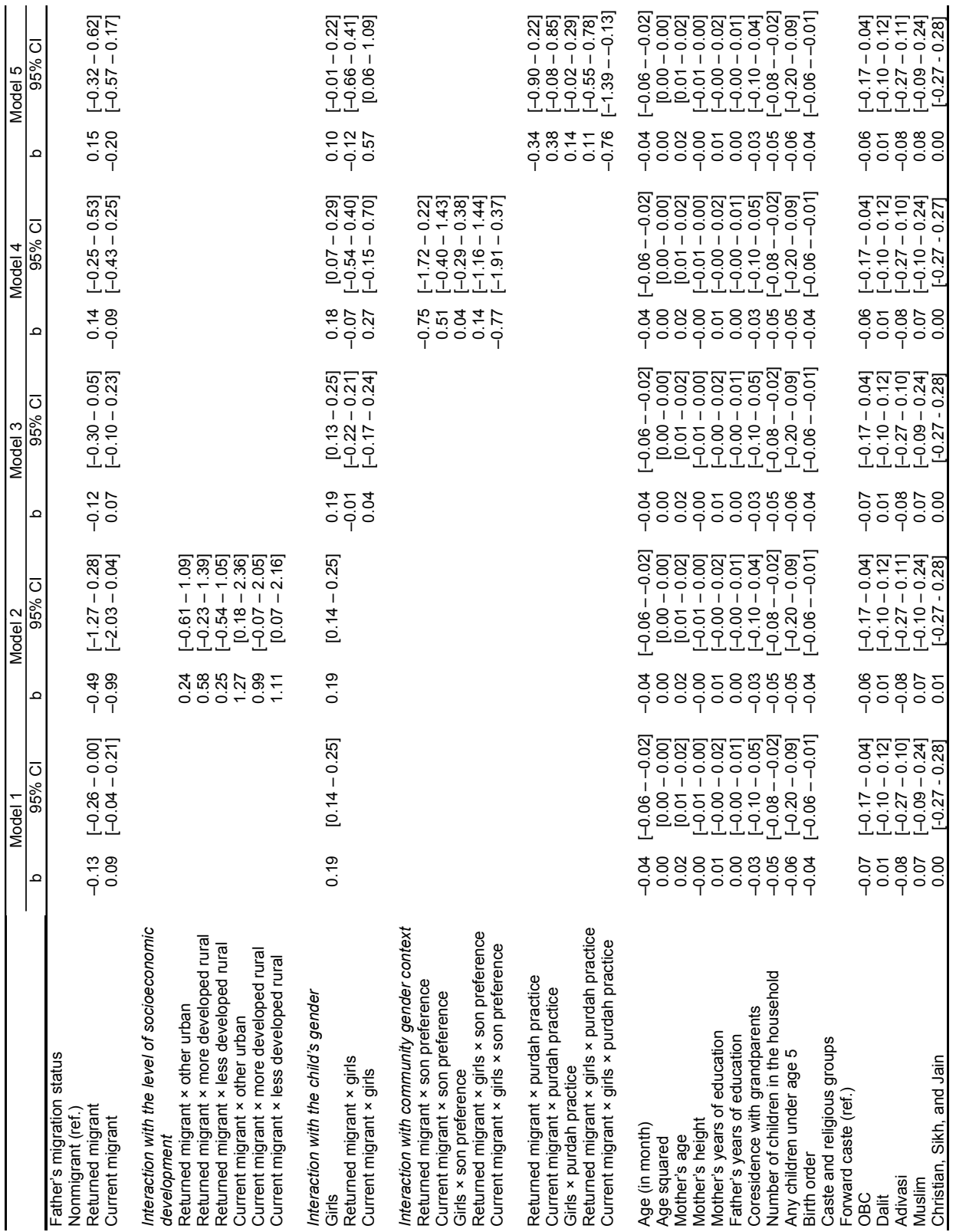




\section{Table 3: (Continued)}

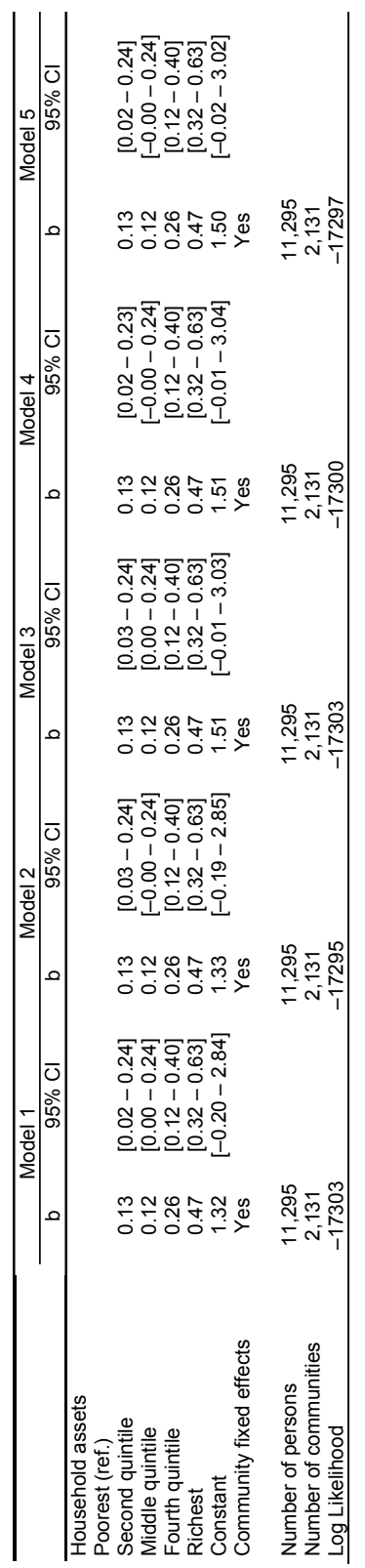


The interaction between father's migration status and children's gender is included in Model 3 in Table 2. The coefficient shows that girls tended to be shorter than boys $(b=-0.17, C I=(-0.23,-0.12))$, but the effects of father's migration status were not different for boys and girls. We further examined whether there were any gender differences in the impacts of a father's out-migration in certain community contexts by including the three-way interaction among father's migration, children's gender, and the community's gender norms in subsequent models. In Model 4, the coefficients for the interaction terms show that the gender gaps in the effects of father's migration status were not conditioned by the levels of son preference in the communities. In Model 5, the coefficient for the interaction between gender and purdah practices $(b=-0.18, C I=$ $(-0.32,-0.04))$ suggested that girls were more disadvantaged in communities where a higher share of women practiced purdah. However, the community-level practice of purdah did not shape how fathers' out-migration influenced boys' and girls' nutritional status.

Table 3 presents the community fixed-effect models predicting BMI-for-age among Indian children. Similar to the effects of migration on children's height, the coefficients in Model 1 show that children of returned migrants tended to have lower BMI-for-age than children of nonmigrants $(\mathrm{b}=-0.13, \mathrm{CI}=(-0.26,0.00))$, while the BMI-for-age of children of current migrants and children of nonmigrants did not differ. In Model 2, we assessed the interaction effects between father's migration status and a community's level of socioeconomic development. The coefficients for the interaction terms indicate that the effects of a father's current absence due to migration varied across communities with different levels of development. We calculated the marginal effects of a father's current absence for the four types of communities at different levels of development while holding other variables at their means. The marginal effects presented in Figure 4 show that a father's absence was associated with lower BMI among children in metropolitan urban communities, predicted higher BMI among children in other urban communities and less developed rural communities, and had minimal effects on the BMI of children in more developed rural communities. 


\section{Figure 4: Marginal effects of father's current migration on BMI-for-age among children 10-15 years old in India, by community socioeconomic development}

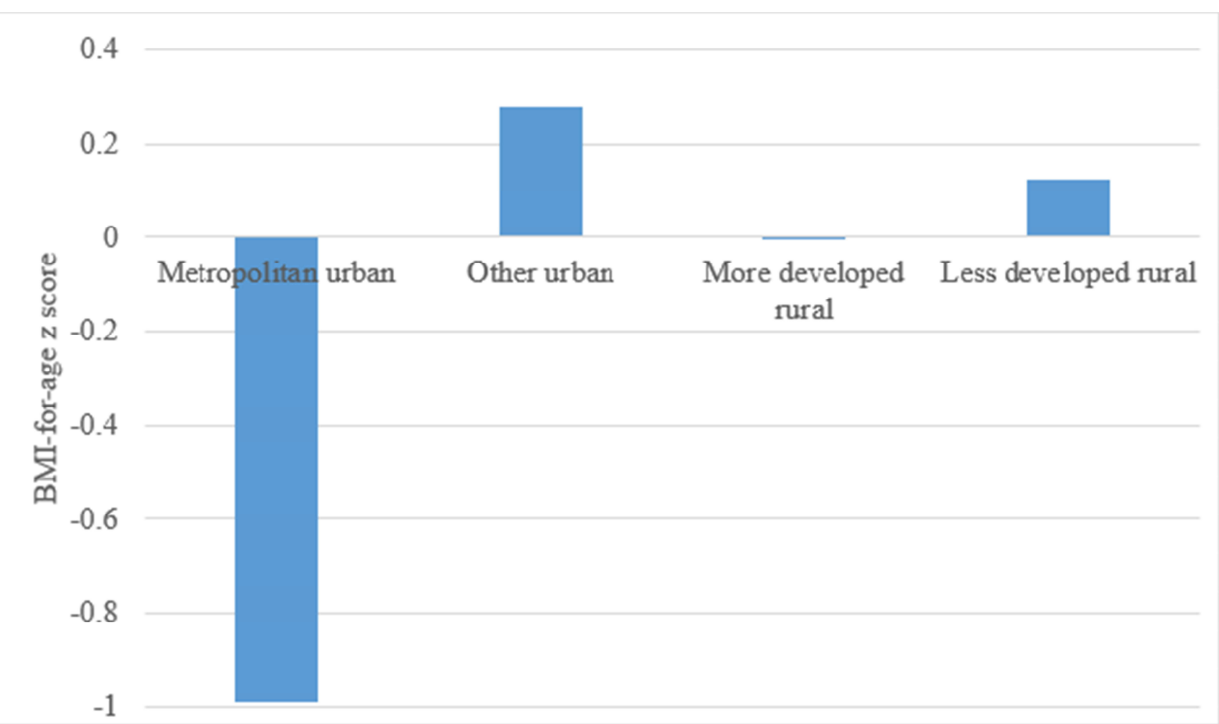

In Model 3 in Table 3, the positive coefficient for gender implies that girls had higher BMI than boys $(\mathrm{b}=0.19, \mathrm{CI}=(0.14,0.25))$. The coefficient for the interaction terms between father's migration status and gender indicate that the influence of father's out-migration on children's BMI did not differ between boys and girls in general. In Models 4 and 5, we further examined whether father's migration status affected boys and girls differently in communities with different gender contexts. The coefficients for the interaction terms in Model 4 reveal no gender gap in the impact of father's migration on children's BMI across communities of different levels of son preference. In Model 5, the coefficient for the three-way interaction among father's current absence, children's gender, and community-level practice of purdah $(b=-0.76$, $\mathrm{CI}=(-1.39,-0.13))$ indicates that gender differences in the effects of father's outmigration were shaped by community gender norms. The marginal effects of a father's current migration were predicted for boys and girls in two extreme situations of community gender contexts: no women practiced purdah, and all women practiced purdah. As presented in Figure 5, father's current migration was associated with lower BMI for boys and higher BMI for girls in gender-egalitarian communities where no one practiced purdah. However, father's current migration increased boys' BMI and 
reduced girls' BMI in communities with severely unequal gender norms where all women practiced purdah.

\section{Figure 5: Marginal effects of father's current migration on BMI-for-age among children 10-15 years old in India, by gender of the child and community gender norms}

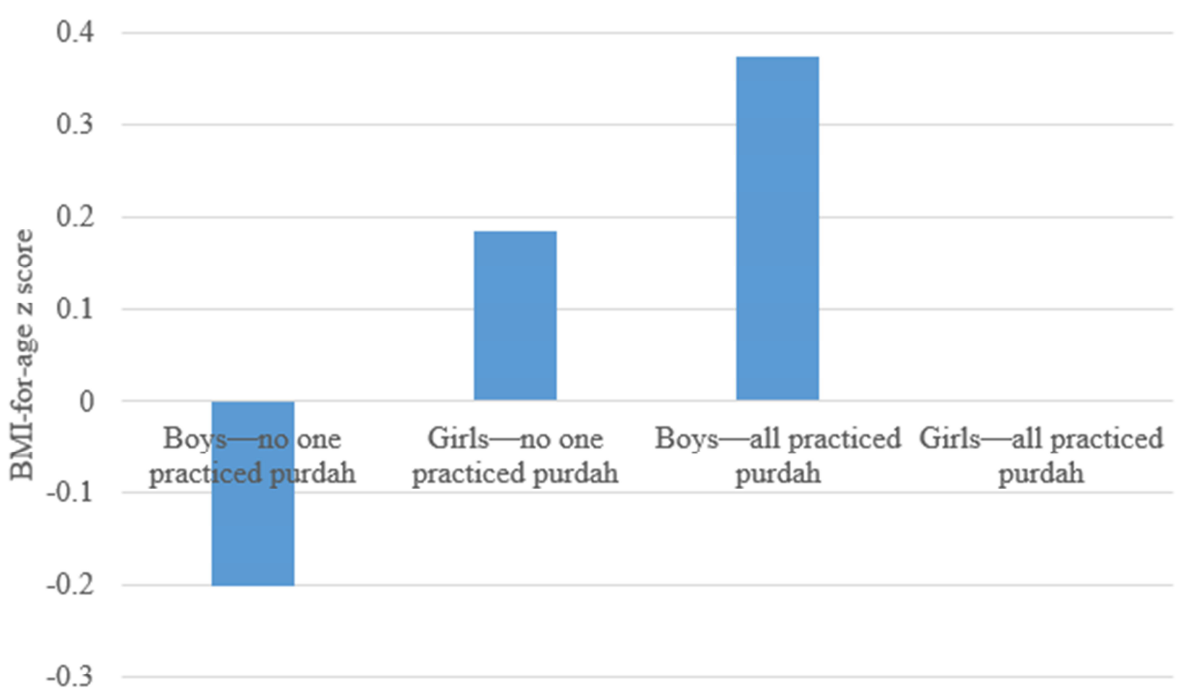

\section{Conclusions and discussion}

Previous studies on the impacts of parental migration on the health and well-being of children staying behind have reported mixed findings, including positive, neutral, and negative effects. In addition to the possible methodological differences among the studies, one important theoretical explanation for the mixed findings is that the impacts of parental out-migration on children are contingent on individual, family, and contextual characteristics. This study has embraced the complexities of this relationship and examined the heterogeneous effects of fathers' migration on the nutritional status of adolescent boys and girls living in different types of communities.

First, we found that children whose fathers were returned migrants had lower heights and BMIs than children of nonmigrants. This relationship was not conditional on community development levels or gender contexts. As shown in previous studies 
using the same data set, returned migrants tend to undertake seasonal work in nearby villages and towns as a survival strategy, whereas currently absent migrants tend to be long-term migrants working in large cities and even abroad for life enhancement (Desai and Chatterjee 2016). Consequently, migrants who travel for short periods and return might be able to send only limited economic remittances, while their absence leads to labor shortages in households and on family farms. Children's nutritional status is thus jeopardized because the positive effect of remittances is not able to compensate for the negative influences of reduced parental time and energy and increased demand for children to help with household chores, farmwork, and caregiving tasks. Currently absent fathers, who usually engage in long-term migration, have less detrimental effects on children's nutritional status, possibly because they can send more economic and social remittances to their households.

This study has also highlighted the role of community contexts in shaping the effects of fathers' out-migration on children's growth. We found that a father's current migration had positive or null effects on the growth of children living in resource-poor contexts but impeded children's growth in socioeconomically developed metropolitan areas. We proposed four potential mechanisms through which a father's out-migration influences children's nutritional status. Remittances and health knowledge are the positive pathways, and the lack of parental attention and increased child responsibility are the negative pathways. The negative effects observed in metropolitan communities could be attributable to the weaker positive mechanisms operating in metropolitan communities than in other communities. First, income and standard of living are higher in metropolitan areas than in other urban and rural communities. So the remittances sent by migrants could make less difference in improving the living conditions of families in metropolitan areas given the high living costs. Based on our data, although the average remittance received by families in metropolitan areas is slightly higher than remittances received by families in other communities, the remittance is equivalent to only one-fifth of household expenditures in the past year in metropolitan communities, which is the lowest rate among all types of communities. Second, a father's out-migration could have a weaker positive impact through the transmission of health knowledge in metropolitan areas because women (the main caretakers) in metropolitan areas are in general more educated and better equipped with health knowledge than women in other communities. Therefore, bringing back health knowledge would not benefit children's health in metropolitan areas as it does in less developed communities. These results help reconcile the findings of previous studies on left-behind children reporting different effects of parental out-migration on children's health. Given that parental migration can influence children's health and growth through countervailing mechanisms, community contexts may determine which mechanisms become more salient, thus leading to different consequences for children's growth. 
The results suggest that a father's current absence is more detrimental to the nutritional status of girls than boys in communities with traditional gender norms, indicated by a high proportion of women practicing purdah. The preference for female seclusion tends to confine women to the domestic realm and prevent them from participating in activities in public spaces, including labor market activities. Therefore, families expect low returns on girls' education in the labor market and are less motivated to invest in girls than in boys. In such communities, remittances are more likely to be used to improve boys' nutrition, while caregivers devote less time and attention to girls after a father's out-migration. By confining women to the domestic realm, the practice of female seclusion also helps solidify women's responsibilities in household work and caregiving. When the out-migration of fathers leads to a shortage of household labor, adolescent girls, rather than boys, are expected to help with household chores, farmwork, and caring for family members. The added responsibilities may expose girls to more infectious diseases, lead to a higher energy consumption, and thereby cause undernutrition.

This research is not without its limitations. First, community gender contexts were measured by two items reflecting a narrow aspect of gender norms in Indian society. Future research could consider other gender-related norms, such as the practice of dowry, women's decision-making power, and parents' relationships with sons and daughters. Second, including community fixed effects controlled for all the communitylevel observed and unobserved confounders, but we were unable to infer causal relationships between father's migration and children's nutritional status. Unmeasured individual and family characteristics could confound this relationship. Third, although we found a negative impact of father's migration on children's physical growth in metropolitan areas, the estimation was based on a small number of cases in the sample. We encourage future researchers on left-behind children and family members in India to oversample families with out-migrants in large metropolitan areas to capture this relatively small population.

In sum, this research reveals the complexities in the relationship between father's out-migration and children's growth. First, by distinguishing between returned migrants and current migration, this study reveals that different types of migration can have distinct effects on left-behind children. Future researchers are encouraged to study whether the impacts of out-migration on children vary by other characteristics of migration, including duration, remittances, destinations, and distance. Moreover, this paper highlights the importance of considering the possible heterogeneous effects of migration on the health and well-being of left-behind family members across different community contexts. In particular, how gender role expectations and ideologies operate at the family and community levels needs to be considered when examining the 
influence of parental out-migration on the developmental outcomes of children in countries with ingrained gender inequality.

In addition to geographic variability, researchers also need to account for the temporal variation in the health effects of migration. India has recently imposed national lockdown to prevent the spread of COVID-19. However, lockdown has had a devastating impact on migrant workers and their families. Many migrants have lost jobs but are not able to return home due to the shutdown of transportation services. Some migrants stay in government shelters with inferior conditions, some are stuck in cities without housing or sufficient food, and others choose to walk back to their villages (Biswas 2020). The health of migrants will suffer during the lockdown, and the risks of contracting the virus in shelters and during the trip home will increase. Further, the health and well-being of family members staying behind will also be negatively impacted by the job losses of the migrants and the difficulty of managing daily life during the lockdown in the absence of migrant men. Future research is needed to examine the implications of the lockdown on the health of migrant workers and their families in India in the short and long terms. 


\section{References}

Abu-Ali, A. and Reisen, C.A. (1999). Gender role identity among adolescent Muslim girls living in the US. Current Psychology 18(2): 185-192. doi:10.1007/s12144999-1027-x.

Aghajanian, A., Alihoseini, J., and Thompson, V. (2014). Husband's circular migration and the status of women left behind in lamerd district, iran: A pilot study. Asian Population Studies 10(1): 40-59. doi:10.1080/17441730.2013.840082.

Amato, P.R. (2000). The consequences of divorce for adults and children. Journal of Marriage and Family 62(4): 1269-1287. doi:10.1111/j.1741-3737.2000.0126 9.x.

Amato, P.R. (2001). Children of divorce in the 1990s: An update of the Amato and Keith (1991) meta-analysis. Journal of Family Psychology 15(3): 355-370. doi:10.1037/0893-3200.15.3.355.

Amuedo-Dorantes, C. and Pozo, S. (2011). New evidence on the role of remittances on healthcare expenditures by mexican households. Review of Economics of the Household 9(1): 69-98. doi:10.1007/s11150-009-9080-7.

Antman, F.M. (2011). The intergenerational effects of paternal migration on schooling and work: What can we learn from children's time allocations? Journal of Development Economics 96(2): 200-208. doi:10.1016/j.jdeveco.2010.11.002.

Antón, J.I. (2010). The impact of remittances on nutritional status of children in Ecuador. International Migration Review 44(2): 269-299. doi:10.1111/j.17477379.2010.00806.x.

Arnold, F., Choe, M.K., and Roy, T.K. (1998). Son preference, the family-building process and child mortality in India. Population Studies 52(3): 301-315. doi:10.1080/0032472031000150486.

Biswas, S. (2020). Coronavirus: India's pandemic lockdown turns into a human tragedy. BBC News. Retrieved from https://www.bbc.com/news/world-asiaindia-52086274.

Botezat, A. and Pfeiffer, F. (2014). The impact of parents migration on the well-being of children left behind-initial evidence from Romania. ZEW-Centre for European Economic Research Discussion Paper (14-029). doi:10.2139/ssrn. 2432946. 
Chang, H., Dong, X.-y., and MacPhail, F. (2011). Labor migration and time use patterns of the left-behind children and elderly in rural China. World Development 39(12): 2199-2210. doi:10.1016/j.worlddev.2011.05.021.

Child Health Epidemiology Reference Group Small-for-Gestational-Age/Preterm Birth Working Group (2015). Short maternal stature increases risk of small-forgestational-age and preterm births in low-and middle-income countries: Individual participant data meta-analysis and population attributable fraction. The Journal of Nutrition 145(11): 2542-2550. doi:10.3945/jn.115.216374.

Christian, P. and Smith, E.R. (2018). Adolescent undernutrition: Global burden, physiology, and nutritional risks. Annals of Nutrition and Metabolism 72(4): 316-328. doi:10.1159/000488865.

Coley, R.L. and Medeiros, B.L. (2007). Reciprocal longitudinal relations between nonresident father involvement and adolescent delinquency. Child Development 78(1): 132-147. doi:10.1111/j.1467-8624.2007.00989.x.

Davis, J. and Brazil, N. (2016). Migration, remittances and nutrition outcomes of leftbehind children: A national-level quantitative assessment of Guatemala. PloS One 11(3): e0152089. doi:10.1371/journal.pone.0152089.

Davis, M.H. and Franzoi, S.L. (1991). Stability and change in adolescent selfconsciousness and empathy. Journal of Research in Personality 25(1): 70-87. doi:10.1016/0092-6566(91)90006-C.

Dawson, D.A. (1991). Family structure and children's health and well-being: data from the 1988 National Health Interview Survey on child health. Journal of Marriage and the Family 53(3): 573-584. doi:10.2307/352734.

De Brauw, A. and Rozelle, S. (2008). Migration and household investment in rural China. China Economic Review 19(2): 320-335. doi:10.1016/j.chieco.2006.10. 004 .

De Haan, A. (1997). Unsettled settlers: Migrant workers and industrial capitalism in Calcutta. Modern Asian Studies 31(4): 919-949. doi:10.1017/S0026749X00 017200 .

Department of Economic and Social Affairs (2016). International migration report 2015. New York: United Nations.

Desai, S. and Andrist, L. (2010). Gender scripts and age at marriage in India. Demography 47(3): 667-687. doi:10.1353/dem.0.0118. 
Desai, S. and Chatterjee, E. (2016). Male migration from rural India: Divergent pathways to long-term and circular migration. Paper presented at the Population Association of America, Washington D.C., March 31-April 2, 2016.

Desai, S., Vanneman, R., and National Council of Applied Economic Research, N.D. (2011-12). India Human Development Survey-II (IHDS-II). ICPSR36151-v2. Ann Arbor, MI: Inter-University Consortium for Political and Social Research.

Deshingkar, P., Sharma, P., Kumar, S., Akter, S., and Farrington, J. (2008). Circular migration in Madhya Pradesh: Changing patterns and social protection needs. European Journal of Development Research 20(4): 612-628. doi:10.1080/09578810802464920.

Dillon, M. and Walsh, C.A. (2012). Left behind: The experiences of children of the Caribbean whose parents have migrated. Journal of Comparative Family Studies 43(6): 871-902. doi:10.3138/jcfs.43.6.871.

Dyson, T. and Moore, M. (1983). On kinship structure, female autonomy, and demographic behavior in India. Population and Development Review 9(1): 3560. doi:10.2307/1972894.

Gibson, J., McKenzie, D., and Stillman, S. (2011). What happens to diet and child health when migration splits households? Evidence from a migration lottery program. Food Policy 36(1): 7-15. doi:10.1016/j.foodpol.2010.08.003.

Graham, E. and Jordan, L.P. (2011). Migrant parents and the psychological well-being of left-behind children in Southeast Asia. Journal of Marriage and Family 73(4): 763-787. doi:10.1111/j.1741-3737.2011.00844.x.

Graham, E. and Jordan, L.P. (2013). Does having a migrant parent reduce the risk of undernutrition for children who stay behind in South-East Asia? Asian and Pacific Migration Journal 22(3): 315-347. doi:10.1177/011719681302200302.

Gulati, L. (1993). In the absence of their men: The impact of male migration on women. New Delhi: Sage Publications.

Haboubi, G.J. and Shaikh, R.B. (2009). A comparison of the nutritional status of adolescents from selected schools of South India and UAE: A cross-sectional study. Indian Journal of Community Medicine: Official Publication of Indian Association of Preventive and Social Medicine 34(2): 108. doi:10.4103/09700218.51230 . 
Hadi, A. (1999). Overseas migration and the well-being of those left behind in rural communities of Bangladesh. Asia-Pacific Population Journal 14(1): 43-58. doi:10.18356/cb7d0c96-en.

Hamilton, E.R. and Choi, K.H. (2015). The mixed effects of migration: Communitylevel migration and birthweight in Mexico. Social Science and Medicine 132: 278-286. doi:10.1016/j.socscimed.2014.08.031.

Hildebrandt, N. and McKenzie, D.J. (2005). The effects of migration on child health in Mexico. Policy Research Working Paper Series, 3573. The World Bank. doi:10.1596/1813-9450-3573.

Huang, Y., Song, Q., Tao, R., and Liang, Z. (2018). Migration, family arrangement, and children's health in China. Child Development 89(2): e74-e90. doi:10.1111/ cdev.12699.

Hugo, G. (2002). Effects of international migration on the family in Indonesia. Asian and Pacific Migration Journal 11(1): 13-46. doi:10.1177/011719680201100 102.

Jordan, L.P. and Graham, E. (2012). Resilience and well-being among children of migrant parents in South-East Asia. Child Development 83(5): 1672-1688. doi:10.1111/j.1467-8624.2012.01810.x.

Kandel, W. and Kao, G. (2001). The impact of temporary labor migration on Mexican children's educational aspirations and performance. International Migration Review 35(4): 1205-1231. doi:10.1111/j.1747-7379.2001.tb00058.x.

Lahaie, C., Hayes, J.A., Piper, T.M., and Heymann, J. (2009). Work and family divided across borders: The impact of parental migration on Mexican children in transnational families. Community, Work and Family 12(3): 299-312. doi:10.1080/13668800902966315.

Lawler, M. and Nixon, E. (2011). Body dissatisfaction among adolescent boys and girls: the effects of body mass, peer appearance culture and internalization of appearance ideals. Journal of Youth and Adolescence 40(1): 59-71. doi:10.1007/s10964-009-9500-2.

Lu, Y. (2015). Internal migration, international migration, and physical growth of leftbehind children: A study of two settings. Health and Place 36: 118-126. doi:10.1016/j.healthplace.2015.09.008.

Mberu, B.U. (2006). Internal migration and household living conditions in Ethiopia. Demographic Research 14(21): 509-540. doi:10.4054/DemRes.2006.14.21. 
McKenzie, D. (2005). Beyond remittances: the effects of migration on Mexican households. In: Özden, Ç. and Schiff, M. (eds.). International migration, remittances and the brain drain. New York: McMillan and Palgrave: 123-147.

McLanahan, S. and Sandefur, G. (1994). Growing up with a single parent. What hurts, what helps. Cambridge: Harvard University Press.

$\mathrm{Mu}, \mathrm{R}$. and De Brauw, A. (2015). Migration and young child nutrition: evidence from rural China. Journal of Population Economics 28(3): 631-657. doi:10.1007/s0 0148-015-0550-3.

Murphy, R., Zhou, M., and Tao, R. (2016). Parents' migration and children's subjective well-being and health: evidence from rural China. Population, Space and Place 22(8): 766-780. doi:10.1002/psp.1955.

Nguyen, C.V. (2016). Does parental migration really benefit left-behind children? comparative evidence from Ethiopia, India, Peru and Vietnam. Social Science and Medicine 153: 230-239. doi:10.1016/j.socscimed.2016.02.021.

Office of the Registrar General and Census Commissioner (2011). Provisional -D-5 migrants by place of last residence, age, sex, reason for migration and duration of residence -2011 .

Onis, M.D., Onyango, A.W., Borghi, E., Siyam, A., Nishida, C., and Siekmann, J. (2007). Development of a WHO growth reference for school-aged children and adolescents. Bulletin of the World Health Organization 85(9): 660-667. doi:10.2471/BLT.07.043497.

Ren, Q. and Treiman, D.J. (2016). The consequences of parental labor migration in China for children's emotional wellbeing. Social Science Research 58: 46-67. doi:10.1016/j.ssresearch.2016.03.003.

Sharma, U. (1990). Public employment and private relations: Women and work in India. In: Stichter, S. and Parpart, J. (eds.). Women, employment and the family in the international division of labour. Philiadelphia: Temple University Press: 229-246. doi:10.1007/978-1-349-20514-1_10.

Stroope, S. (2015). Seclusion, decision-making power, and gender disparities in adult health: examining hypertension in India. Social Science Research 53: 288-299. doi:10.1016/j.ssresearch.2015.05.013.

Taylor, J.E., Rozelle, S., and De Brauw, A. (2003). Migration and incomes in source communities: A new economics of migration perspective from China. Economic Development and Cultural Change 52(1): 75-101. doi:10.1086/380135. 
Tong, Y., Luo, W., and Piotrowski, M. (2015). The association between parental migration and childhood illness in rural China. European Journal of Population 31(5): 561-586. doi:10.1007/s10680-015-9355-z.

Wang, F., Ping, R., Zhan, S., and Shen, A. (2005). Reproductive health status, knowledge, and access to health care among female migrants in Shanghai, China. Journal of Biosocial Science 37(5): 603-622. doi:10.1017/S00219320 04006844 .

Wen, M. and Lin, D. (2012). Child development in rural China: Children left behind by their migrant parents and children of nonmigrant families. Child Development 83(1): 120-136. doi:10.1111/j.1467-8624.2011.01698.x.

Wen, M., Su, S., Li, X., and Lin, D. (2015). Positive youth development in rural China: The role of parental migration. Social Science and Medicine 132: 261-269. doi:10.1016/j.socscimed.2014.07.051.

$\mathrm{Xu}, \mathrm{H}$. and Xie, Y. (2015). The causal effects of rural-to-urban migration on children's well-being in China. European Sociological Review 31(4): 502-519. doi:10.1093/esr/jcv009.

Ye, J. and Pan, L. (2011). Differentiated childhoods: impacts of rural labor migration on left-behind children in China. The Journal of Peasant Studies 38(2): 355-377. doi:10.1080/03066150.2011.559012. 


\section{Appendix}

Table A-1: Percentages of children in migrant households by child's gender and community type

\begin{tabular}{|c|c|c|c|c|c|c|c|}
\hline & \multicolumn{2}{|c|}{ Gender } & \multicolumn{4}{|c|}{ Community type } & \multirow[b]{2}{*}{ Total } \\
\hline & Boy & Girl & $\begin{array}{l}\text { Metropolitan } \\
\text { urban }\end{array}$ & $\begin{array}{l}\text { Other } \\
\text { urban }\end{array}$ & $\begin{array}{l}\text { More developed } \\
\text { rural }\end{array}$ & $\begin{array}{c}\text { Less } \\
\text { developed rural } \\
\end{array}$ & \\
\hline \multicolumn{8}{|c|}{ Father's migration status } \\
\hline Nonmigrant & 5,248 & 4,767 & 720 & 2,741 & 3,118 & 3,436 & 10,015 \\
\hline$(\%)$ & 89.21 & 88.08 & 97.56 & 93.87 & 86.93 & 84.84 & 88.67 \\
\hline Returned migrant & 297 & 318 & 10 & 67 & 209 & 329 & 615 \\
\hline (\%) & 5.05 & 5.88 & 1.36 & 2.29 & 5.83 & 8.12 & 5.44 \\
\hline Current migrant & 338 & 327 & 8 & 112 & 260 & 285 & 665 \\
\hline$(\%)$ & 5.75 & 6.04 & 1.08 & 3.84 & 7.25 & 7.04 & 5.89 \\
\hline Total N & 5,883 & 5,412 & 738 & 2,920 & 3,587 & 4,050 & 11,295 \\
\hline
\end{tabular}


Lei, Desai \& Chen: Fathers' migration and nutritional status of children in India 